\title{
Cholesterol lowering does have a role in secondary prevention
}

Coronary artery disease has a dynamic pathology, which is progressive without treatment, and for most patients who present with symptoms of coronary heart disease (CHD) this will be their ultimate cause of death. Though our first responsibility as cardiologists is to diagnose and treat by relieving symptoms of exertional angina and limiting the amount of myocardial damage in an evolving infarction, we also have a responsibility to consider the antecedents of CHD and how the risk of a further major ischaemic event can be reduced. ${ }^{1}$

Stopping smoking, ${ }^{2}$ modifying diet $^{3-5}$ (decreasing saturated fat and increasing polyunsaturated fats, the latter particularly from marine sources), and taking more aerobic exercise ${ }^{6}$ are all important steps patients can take to reduce their risk of further morbidity and improve their chances of survival. In making these lifestyle changes patients will also reduce the need for physicians to intervene in relation to blood pressure, lipoproteins, and glucose. None the less, measuring and effectively managing these risk factors, in the light of best current scientific evidence, is our responsibility. Optimal blood pressurc control is part of good clinical practice, and although there is no convincing evidence in coronary patients from control trials, an overview of primary prevention studies shows that tempering blood pressure will certainly reduce the risk of stroke and may also reduce coronary disease. ${ }^{7}$ For cholesterol the evidence from earlier secondary prevention trials was not convincing and overviews, ${ }^{8}$ while suggesting treatment benefit in relation to coronary mortality, left open the question of survival. ${ }^{9} \mathrm{With}$ the development of more powerful and better tolerated drugs, a new generation of cholesterol lowering trials are now being concluded in patients with coronary disease.

Angiographic trials ${ }^{10}$ showed the effectiveness of cholesteral lowering using interventions ranging from lifestyle programmes, diet together with drugs (statins, resins, and nicotinic acid), or partial ileal bypass surgery on angiographic disease. A significant reduction in the rate of disease progression was reported in almost every trial and in some trials there was evidence of disease regression; in the MAAS trial the number of new lesions was also significantly reduced. ${ }^{11}$ Though these luminal changes are real they are rather small and their clinical import has remained in doubt despite $\mathrm{POSCH},{ }^{12}$ which slowed disease progression by lowering cholesterol using partial ileal bypass surgery, and reported significantly fewer revascularisations (CABG), non-fatal re-infarctions and atherosclerotic coronary deaths, and a favourable long-term trend in survival ${ }^{13}$ which was the primary end point of that study. The Scandinavian Simvastatin Survival Study $(4 S)^{14}$ has now reported and is the first secondary prevention trial to show that cholesterol lowering results in a reduction in total mortality. 4444 patients up to 70 years old with coronary disease (about three quarters had had a myocardial infarction and the rest had angina alone with objective evidence of ischaemia on the electrocardiogram or confirmation of disease on angiography) were randomised to simvastatin or placebo in 94 clinical centres from five countries in double blind trial. Patients were recruited if their total cholesterol remained between 5.5 and $8.0 \mathrm{mmol} / \mathrm{l}$ after a few weeks on diet and a short run in on open placebo. For the patients randomised mean total cholesterol was $6.75 \mathrm{mmol} / \mathrm{l}$, LDL cholesterol $4.90 \mathrm{mmol} / \mathrm{l}$, HDL cholesterol $1.2 \mathrm{mmol} / \mathrm{l}$, and fasting triglycerides $1.5 \mathrm{mmol} / \mathrm{l}$. Most patients achieved the target of a total cholesterol concentration of between 3.0 and $5.2 \mathrm{mmol} / 1$ on $20 \mathrm{mg}$ of simvastatin daily; about a third had to increase the dose to $40 \mathrm{mg}$ after six or more weeks. Compliance with drug therapy was high (90\%), almost identical to those taking placebo, and active drug was well tolerated with few side effects. Complete follow up of patients was achieved over a mean of 5.4 years. The primary end point was total mortality, and on an intention to treat analysis the risk $(95 \% \mathrm{CI})$ of death from all causes was $0.70(0.58$ to 0.85$)$, and the risk of all coronary deaths was $0.58(0.46$ to 0.73$)$ in the simvastatin group. This improvement in survival was achieved without an increase in non-CHD mortality, including deaths from cancer. All major coronary events (non-fatal and silent myocardial infarction together with coronary deaths) were together reduced by $34 \%$ in the simvastatin group and there was also a $37 \%$ lower requirement for coronary artery surgery. Women made up about a fifth of the total sample, and apart from total mortality their results for coronary mortality and nonfatal (re)infarction were similar to those of the men. This is consistent with two of the other three secondary prevention trials that included women. ${ }^{15}$ This important overall result for total mortality is consistent with the direction of long-term benefit in the POSCH study, ${ }^{12}{ }^{13}$ the 15 year follow up results of patients treated with niacin in the Coronary Drug Project, ${ }^{16}$ and the final report of the Stockholm Ischaemic Heart Disease Secondary Prevention Study. ${ }^{17}$ The authors of the $4 S$ study estimate that for 100 patients treated with simvastatin over six years about four lives will be saved from nine expected coronary deaths, seven myocardial (re)infarctions will be postponed out of 21 expected, and six fewer revascularisation procedures will be required out of 19 expected operations.

Cholesterol lowering can now be added to the list of treatments-aspirin, $\beta$ blockers, ACE inhibitors, and anticoagulants-that have each been shown to reduce the risk of coronary death and improve survival in selected patients with CHD. For a patient recovering from a myocardial infarction with no angina the prospect of taking up to five drugs is daunting: those with symptoms will also need antianginal drugs and possibly blood pressure lowering and diabetic drugs as well. Such a formidable prescription makes long-term patient compliance unlikely. There is a need to be selective about the clinical indications for these different treatments. All coronary patients should take aspirin once a day. ${ }^{18}$ The evidence suggests that those most likely to benefit from $\beta$ blockers are those patients following myocardial infarction who are at highest risk because of electrical or mechanical 
complications. ${ }^{1920}$ ACE inhibitors are indicated in those patients with significant left ventricular dysfunction..$^{21} 22$ These higher risk patients were not included in $4 S$ to avoid excess early mortality from congestive heart failure or arrhythmias. This might have diluted the effect of simvastatin on deaths caused by progression of coronary atheroselerosis. So patients eligible for cholesterol lowering from $4 \mathrm{~S}$ are those with angina or myocardial infarction, in whom total cholesterol is greater than $5.5 \mathrm{mmol} / \mathrm{l}$ on at least three occasions, despite optimal dietary intervention. Long-term anticoagulation after infarction ${ }^{23}$ is unusual in the United Kingdom except for patients at risk of systemic embolisation. In addition to medical treatment surgery is justified on prognostic grounds in patients with disease of the left main stem (or left main stem equivalent) or three vessel disease, especially in the presence of impaired left ventricular function. ${ }^{24}$

In managing coronary patients over the long term it is necessary to consider how the risk of a further major ischaemic event can be reduced. By advising lifestyle changes in relation to smoking, diet, and exercise, together with measuring and effectively managing blood pressure, lipoproteins and glucose, and using appropriate drug therapy in selected patients we can make an important contribution towards reducing morbidity, including hospital admissions and the need for revascularisation, as well as postponing mortality from this disease for a few years. To translate current scientific evidence into clinical practice requires all cardiologists and surgeons to embrace prevention as an integral part of day-to-day practice. ${ }^{1}$ Offering words of encouragement on coronary care rounds and giving a health promotion leaflet in a busy outpatient department is not enough. We need a comprehensive preventive cardiology programme that brings together those health professionals, including general practitioners, who can help patients to change the way they live, and which ensures effective long-term management of risk factors and the selective use of drug treatments of proven benefit.

DAVID A WOOD

Royal Brompton Hospital,

National Heart and Lung Institute,

University of London

1 Pyörälä K, De Backer G, Graham I, Poole-Wilson P, Wood DA on behalf of the Task Force. Prevention of coronary heart disease in clinical practice. Recommendations of the Task Force of the European Society of Cadiology, European Atherosclerosis Society and European Society of Hypertension. Eur Heart f 1994;15:1300-31.

2 Áberg A, Bergstrand R, Johansson S, Ulvenstam G, Vedin A, Wedel H, et al. Cessation of smoking after myocardial infarction. Effects on mortality after 10 years. Br Heart $\mathcal{f} 1983 ; 49: 416-22$.

3 Leren P. The Oslo Diet-Heart Study: eleven-year report. Circulation 1970;42:935-42

4 Burr ML, Gilbert JF, Holliday RM, Elwood PC, Fehily AM, Rogers S, et al. Effects of changes in fat, fish and fibre intakes on death and myocardial reinfarction; diet and reinfarction trial (DART). Lancet 1989;344:757-61

5 Lorgeril M, Renaud S, Mamelle N, Salen P, Martin JL, Monjaud I, et al. Mediterranean alpha-linoleic acid-rich diet in secondary prevention of coronary heart disease. Lancet 1994;343:1454-9.

6 O'Connor GT, Buring JF, Yusuf S, et al. An overview of randomised trials of rehabilitation with exercise after myocardial infarction. Circulation 1989;60:234-44.

7 Collins R, Peto R, MacMahon S, et al. Blood pressure stroke and coronary disease. Part 2. Short-term reductions in blood pressure: overview of randomized drug trials in their epidemiological context. Lancet 1990; 335:827-38.

8 Roussouw JE, Lewis B, Rifkind BM. The value of lowering cholesteral after myocardial infarction. $N$ Engl Med $¥$ 1990;323:1112-9.

9 Holme I. An analysis of randomized trials evaluating the effect of cholesterol reduction on total mortality and coronary heart disease incidence. terol reduction on total mortalit

10 Vos J, de Feyter PJ, Simoons ML, Tijssen JGP, Deckers JW. Retardation and arrest of progression or regression of coronary artery disease: a review. Prog Cardiovasc Dis 1993;35:435-54.

11 MAAS Investigators. Effect of simvastatin on coronary atheroma: the multicentre anti-atheroma study (MAAS). Lancet 1994;344:633-8.

12 Buchwald H, Varco RL, Matts JP, et al. Effect of partial ileal bypass surgery on mortality and morbidity from coronary heart disease in patients with hypercholesterolemia: report of the Program on the Surgical Control of the Hyperlipidaemias (POSCH). $N$ Engl $f$ Med 1990;323:946-55.

13 Buchwald H, Campos CT, Boen JR, et al. Disease-free interval assessments after partial ileal by pass in coronary heart disease patients [abstr]. $\mathcal{F}$ Am Coll Cardiol 1994;23:389.

14 Scandinavian Simvastatin Survival Study Group. Randomised trial of cholesterol lowering in $\mathbf{4 4 4 4}$ patients with coronary heart disease: the Scandinavian Simvastatin Survival Study (4S). Lancet 1994;344: 1383-9.

15 Law MR, Wald NJ, Thompson SG. By how much and how quickly does reduction in serum cholesteral concentration lower risk of ischaemic reduction in serum cholesteral concentration
heart disease? $\mathrm{BrM}$ ed $\mathcal{F} 1994 ; 308: 367-73$.

16 Canner PJ, Berge KG, Wenger NK, et al, for the Coronary Drug Project Group. Fifteen years mortality in coronary drug project patients: longterm benefit with niacin. F Am Coll Cardiol 1986;8:1245-55.

17 Carlson LA, Rosenhamer G. Reduction of mortality in Stockholm Ischaemic Heart Disease Secondary Prevention Study by combined treatment with clofibrate and nictotinic acid. Acta Med Scand 1988; 223:405-18.

18 Antiplatelet Trialists' Collaboration. Collaborative overview of randomised trials of antiplatelet therapy. I. Prevention of death, myocardial infarction, and stroke by therapy in various categories of patients. $B M \mathcal{F}$ 1994;308:81-106.

19 Yusuf S, Peto R, Lewis J, Collins R, Sleight P. Beta-blockade during and after myocardial infarction: an overview of the randomized trials. Prog Cardiovasc Dis 1985;27:335-71.

20 Furberg CD, Hawkins CM, Lichstein F. Effect of propranolol in postinfarction patients with mechanical and electrical complications. farction patients with
Circulation 1983;69:761-5

21 Pfeffer MA, Braunwald E, Moye LA, Basta L, Brown EJ, Cuddy TE, et al. Effect of captopril on mortality and morbidity in patients with left ventricular dysfunction after myocardial infarction. N Engl f Med 1992; 327:669-77

22 AIRE (Acute Infarction Ramipril Efficacy) Investigators. Effect of ramipril on mortality and morbidity of survivors of acute myocardial infarction with clinical evidence of heart failure. Lancet 1993;342:821-8

23 Smith P, Arnesen H, Holme I. The effect of warfarin on mortality and reinfarction after myocardial infarction. $N$ Engl $\Im$ Med 1990;323:147-52.

24 Rahimtoola SH. Perspective on the three large multicentre randomized clinical trials of coronary by-pass surgery for chronic stable angina. Circulation 1985;72(suppl V):123-35. 